\title{
Reform Discussion of Education Management Model in Big Data Era
}

\author{
Bo Zhao', Congling Huang ${ }^{2}$ \\ ${ }^{1}$ Shaanxi Costume Engineering University, Xixian, Shaanxi, China \\ ${ }^{2}$ Yangling Vocational \& Technical College, Yangling, Shaanxi, China
}

Keywords: big data; education; education management; management reform

\begin{abstract}
With the arrival of the era of big data, people's daily life, entertainment and learning are all occupied by the Internet. The traditional education management model faces enormous challenges. New technologies are changing the concepts of teachers and students. The new education management system is replacing the old management system. This paper mainly discusses the education management model reform measures in the era of big data for reference by relevant personnel.
\end{abstract}

\section{Introduction}

At present, big data technology is developing rapidly and applied by people in all walks of life. The education industry needs to keep up with the trend of the times and use the advantages of big data technology to complete the reform of education management model as soon as possible, and actively solve the problems of a single mode of teaching and the backwardness of student evaluation models. Disadvantages can maximize the development of education [1]. The education reform work in our country has been going on for a long time and has achieved outstanding results. Whether or not we can do a good job in reforming the education model in the era of big data depends largely on the wisdom of the relevant teachers and the determination of the school.

\section{The Concept of Big Data}

Nature magazine launched a cover column entitled "Big Data" in September 2008, telling about the increasingly important role of data in mathematics, physics, biology, engineering, and socioeconomics. Gary King said: "This is a revolution. The huge data resources have led to a quantified process in all fields. No matter academia, business or government, all fields will begin this process." Big data also claims huge amounts of information. It means that the amount of data involved is so large that it cannot be accessed through the current mainstream software tools. It can be retrieved, processed, and organized in a reasonable amount of time to become a variety of information to help companies make better business decisions [1]. At the same time, data related to big data is also available. Areas such as storage, data security, and data analysis also belong to the category of big data.

\section{The Impact of Big Data on Teaching}

In the field of education, in addition to embodying all the macro functions of traditional data, big data can also collect and analyze detailed micro-personalized data, and the advantages of big data emerge. Traditional data interpret the macro and overall educational status; big data is used to adjust educational behavior and achieve personalized education; traditional data are derived from periodic, targeted assessments, and the sampling process may have systemic errors; big data come from procedural, the third-party, technical observation sampling method has less error [2]. The talents, professional skills, and facilities and equipment required for traditional data analysis are relatively common and easy to obtain; the talents, professional skills and facilities and equipment required for big data mining are high, and practitioners need to have the inspiration of innovation awareness and data mining, step by step. 
Big Data has brought a wave of new rounds of educational informatization. With the rapid innovation of hardware and the high intelligence of software, it has been irresistibly pushed to us. As the education administrator of the new era, only the "surfing" technology is well-controlled, education ideas are changed, the school's management of big data services is used in time, education and teaching are reformed, and the quality of education is improved [2].

\section{Role of Educational Management Reform in Big Data Era}

With the development of the times and the ever-changing science and technology, the previous teaching management model is slowly withdrawing from the stage of history. This new management model based on modern information technology and big data as a carrier has greatly realized the sharing and full use of educational resources, promoted the improvement of work efficiency, changed work efficiency, made the work more timely and scientific [1].

\subsection{Model construction of educational big data management.}

As proposed by the National Education Work Conference in 2014, the goal of China's education management in the coming period is to "accelerate the modernization of education governance system and governance capacity.” China's education management model will undergo a qualitative transformation and a big data management model will emerge [1].

The education management model supported by big data: With the core elements of "main body, objects, resources, and goals" as the core elements, an education cloud with multiple levels of connectivity and sharing is established, a complex education and management system is established, cloud technology is used to process education and cloud big data, and public education services are provided [2]. Institutions, teachers, and students provide education resource services, professional development services, and comprehensive quality development services for all-weather, multi-terminal, personalized needs, improve the rationality and fairness of educational resource allocation, and improve the scientific level of educational decision-making. The new model of big data education management is shown in the right figure.

In education management, human factors are important educational data and are the source of all educational data. In the allocation of educational resources, we must first carry out a scientific and reasonable basic classification of resources: human resources, financial resources, and knowledge resources; educational content, educational theory, educational methods, and educational experience, etc. are hidden resources in the allocation of educational resources [3]. However, they are fundamental. Resources; Technical resources are productivity resources for education and management of big data. Educational technologies, especially education, information technology, big data, and cloud technology, are application-type resources that manage the needs of educational entities to meet the needs of educational services and rationally allocate educational resources.

\subsection{Action roadmap for educational big data management.}

Education big data management is a long-term and great project. From the current level of education informatization construction and the challenges it faces, there is still a long way to go. We need to push forward ideologically, theoretically and practically [3]. We urgently need to formulate a correct and long-term road map for action as shown in the figure.

This is a three-level operation strategy: the bottom layer is the construction of big data education and management - education cloud construction, all regions should follow the national education data standards, build distributed education data center (cloud) - resource library + database + The construction of data relationship logic provides basic hardware support for the deployment of cloud education and teaching resources, and then builds a three-tier smart platform - smart campus, wisdom school (classroom) and smart terminals (especially mobile terminals) - application platform construction, also as a basis [4]. At the hierarchical level, big data mining of educational resources the statistics, analysis, modeling, etc., of the data generated during the education process provides data applications for educational management decision-making; at the upper level is the operating system for educational big data management, from the public Serve individual development of 
students, make use of big data to provide equitable allocation and individualized supply of educational resources, advance education development and reforms, enable everyone to enjoy quality and appropriate education resources, promote the sustainable development of education quality, promote education brand building and innovation promote and form an efficient and green education culture.

\subsection{Give more flexibility to the education process.}

In order to maximize the quality and efficiency of teaching, all types of teaching in the new situation should be flexible and forward-looking and should be adapted to the development of modern society as much as possible. Due to the influence of various reasons, the traditional education management model reform work can hardly achieve good results in enhancing the flexibility of the education process, and the reform work under the background of big data is different [4]. The era of big data is different. Internet technology is highly developed, and the popularity of computers allows educators to easily select learning content based on their own needs. This will effectively increase educated learning enthusiasm.

The computer penetration rate in China has reached a relatively high level, and it maintains a relatively stable growth rate. Therefore, many people can use computers for online learning. Since there are certain differences in the amount of knowledge and understanding of each educated person, the courses to which individuals are biased vary [4]. In the era of big data, people can choose courses according to their own needs. More importantly, educators in remote areas can also enjoy the guidance of excellent teachers from all over the country and even from around the world. This not only achieves "on-demand teaching" The purpose of this is also conducive to the popularization of quality education resources, and to a certain extent, it can effectively promote the improvement of the overall knowledge level of educated groups.

\subsection{Facilitate the interaction between students and teachers.}

In traditional education activities, it is often the case that teachers keep teaching and students are taking lessons seriously. However, after the teacher asks questions, it is rare to see students answer [5]. This shows that in previous teaching, the interaction between teachers and students is not strong, and such classroom teaching is often difficult to receive good results. It should be noted that after the emergence of big data technology, students' answers and review and other information can be monitored and recorded by related equipment in a timely manner [5]. Teachers can provide feedback on students' learning in the first time by analyzing students' various learning information. The problem, which can increase the interaction between the students and the teachers to a certain extent, is conducive to the improvement of teacher-student relationship and the improvement of teaching quality.

\section{Methods to Carry out Education Management Model Reform in Big Data Era}

The replacement of information technology is unpredictable, and its coverage and processing capabilities cannot be accurately grasped, but it has always pursued even better development. The construction of university education management informatization should keep pace with the development of the era, and on the basis of clarifying the goal of education construction, it should protect the efficiency of education management [4]. As we all know, the design department of university management is more complicated, and the accuracy and timeliness of information transmission are not good. At this time, how to do a good job in education management reform is particularly important.

\subsection{Vigorously promote information technology reform.}

The advent of the era of big data radically subverts the traditional education management model to meet the needs of teachers and students. At this time, each educator must establish a big data thinking model and be good at carrying out data analysis in order to formulate the best management and promote the smooth implementation of education and education reform. With the wide application of 
big data technology, the educators' experience and the idea of running a university are no longer the dominant causes of teaching. Data-assisted instruction is used to improve the teaching effectiveness of colleges and universities. At the same time, according to the overall development of the school to carry out education informatization reform work, build mutual exchange and sharing platform to meet the public's demand for data. As we all know, building an information management system is the basis for ensuring the smooth implementation of big data technology [6]. Only by establishing a data management system can we fully tap into the effective information brought about by big data and improve the ability of all parties to analyze and process data.

\subsection{Innovate education information management mode.}

The use of big data technology focuses on teaching people how to deal with data problems, that is, tracing the source and finding the main cause of problems, so as to propose appropriate solutions. In the traditional education management model, there are problems such as lack of integrity and poor coherence of data, leading to the one-sidedness and subjectivity of decisions made by policymakers [7]. The use of big data technology will help overcome the above shortcomings in time and solve the above problems more democratically. Education management information requires educators to extensively use computer information technology in management tools, and use education management software to implement efficient, accurate management of course selection, course arrangement, and teaching affairs in daily teaching management, so as to adapt between departments and colleges Management requirements.

\subsection{Improve the quality of teachers.}

Teachers must pay ten or even a hundred times more energy to enhance business learning and management, so that they truly become doubters. Learners who want to become a new era should also have a sense of reform [5]. Based on their mastery of existing professional knowledge, they should constantly absorb advanced science and technology, improve their own overall quality standards, and focus on strengthening their own answers to questions, find resources, and guide students to solve problems. The ability to use all opportunities to understand the operating principles of various information devices, in the learning process has the purpose of improving the data retrieval, storage and other proficiency [5]. It must be noted that in order to mobilize the enthusiasm of teachers as much as possible and give full play to the leading role of outstanding teachers, schools must set up scientific incentive mechanisms and the facts prove that the measures can achieve good results.

\subsection{Strengthen all aspects of information management.}

With the development of university informationization and the development of big data technology, the campus network plays an important role in daily teaching and management. There are many hidden dangers in the teaching and scientific research of teachers and students in colleges and universities, such as: virus intrusion and bad information. At this time, the construction and protection of network security in colleges and universities has become an important part of solving the above problems [6]. Through the intrusion detection system, the vulnerability in the system is scanned, and businesses are promptly urged to update the software to ensure the security of the data. At the stage of big data development, digital management is mainly shown in data collection. To strengthen the university's collection of teaching, scientific research and other aspects, we can reserve certain data and information in order to establish a complete information system. At the same time, by using the collected data information, real data can be obtained in a reasonable manner and the data can be grasped in real time, so as to propose better countermeasures [6]. In addition, in the context of big data, scientific research, management, and other information are integrated, such as teacher information, student privacy, etc. Integrating data information helps maintain the privacy of teachers and students, effectively protects all aspects of data information, and achieves optimal management.

\subsection{Vigorously carry out micro-teaching pilot work.}

In the era of big data, the new concept of "micro-curriculum" emerged in the education industry. It played a significant role in stimulating students' interest in learning and improving teaching 
efficiency. Therefore, in order to effectively encourage teachers to innovate and make full use of network technology and resources, schools should call teachers to actively develop micro-curricular production [7]. It should be particularly pointed out that teachers must pay attention to the design of teaching skill points and knowledge points during the course of making micro-classes. They should widely seek the opinions and suggestions of their peers and students after the micro-classes are made, in order to continuously improve their own micro- Class production level and teaching level.

\subsection{Abandon backward evaluation methods.}

On the whole, most schools in China still only use academic performance as the sole criterion for judging student ability. This not only does not meet the requirements of quality education, but also does not favor the advancement of the education management model reform process in the context of big data. For this reason, schools must abandon the backward student evaluation model, introduce new evaluation methods, and can add evaluation standards for computer operation skills to the evaluation model [7]. This not only breaks the score-first situation in the traditional evaluation model, but also promotes student information literacy. The dramatic increase can also indirectly promote the development of education management model reform.

\subsection{Develop student teamwork and independent thinking skills.}

Independent thinking is extremely important for students. It is an indispensable factor in students' ability to exercise thinking and promote their own all-round development. Students in the era of big data are more convenient in the acquisition of educational resources, which helps to form independent thinking habits [4]. However, it is worth noting that because students learn in a free space for a long time, it is difficult for teachers to effectively track their learning process, which may result in students failing to improve their teamwork ability. The society has a higher requirement for the individual teamwork ability. Therefore, in order to consider the students' future and be responsible for the reform of the education management model in the era of big data, we must do a good job in improving the students' independent thinking ability and teamwork ability.

\section{Conclusion}

Education work is the "strengthening pinpoint" of the country's development and a "booster" for the fate of individuals. Therefore, we must do a good job in the reform of the education management model. The reform of the education management model in the era of big data covers a wide range of content and has a high degree of difficulty. Therefore, it is not only necessary for the relevant teachers to actively improve their overall quality, but also for the school to constantly improve the teaching system. Only in this way can China be maximally promoted.

\section{References}

[1] Y.C. Li, University education management informationization usher in the era of big data, University education, 2015, vol.11, and pp.181-182.

[2] Y.T. Qu, Exploration of Educational Management Reform in the Big Data Era, China Management Informationization, 2016, vol.4, pp.251-253.

[3] A.T. Pan, New Development of Educational Management Informationization: Towards Smart Management, Oriental Education, 2015, vol.2, pp.224-226.

[4] X.T. Ni, Based on the innovation research of campus management informationization in the era of big data, computer knowledge and technology, 2015, vol.10, pp.8-9.

[5] Y.M. Hu, Problems in the Construction of Rural Public Crisis Management Informationization in the Era of Big Data and Countermeasures, Science and Technology Management Research, 2016, vol.12, pp.170-177.

[6] F.Y. Wang and X.Q. Yan, Practice and Exploration of Educational Management 
Informationization in the Era of Big Data, China Education Informatization, 2016, vol.14, pp.46-48. [7] X.L. Zhou, Educational Management Reform in the Age of Big Data, Chinese Journal of Education, 2014, vol.10, pp.25-30. 